\title{
The truth behind the pubic rami fracture: identification of pelvic fragility fractures at a university teaching hospital
}

\author{
Authors: Dawn van Berkel, ${ }^{\mathrm{A}}$ Orly Herschkovich, ${ }^{\mathrm{A}}$ Rachael Taylor, ${ }^{\mathrm{A}}$ Terence Ong ${ }^{\mathrm{A}}$ and Opinder Sahota ${ }^{\mathrm{A}}$
}

\section{Introduction}

Older patients presenting on the acute medical take with pelvic fragility fractures (PFF) represent an increasing epidemic. ${ }^{1}$ The most common pelvic fracture identified by plain X-ray is that of the pubic rami. ${ }^{2} \mathrm{PFF}$ are painful and despite optimal analgesia, many of these patients struggle to mobilise. Between $60 \%$ and $80 \%$ of patients have fractures of the posterior pelvic ring, namely of the sacrum, which are overlooked and not visible on plain X-ray., Sacral fractures are unstable and load-bearing, thus increasing the likelihood of pain-dependent mobility reduction and the risks that this poses in an older population. ${ }^{5}$ Minimally invasive sacroplasty is available and has been shown to improve painrelated outcomes. ${ }^{6,7}$ We aimed to quantify the number of patients progressing to further pelvic imaging in the form of computed tomography (CT) or magnetic resonance imaging (MRI) and the prevalence of combined pubic rami and sacral fractures.

\section{Methods}

We carried out prospective screening of pelvic imaging in patients aged 70 years or over presenting to Nottingham University Hospitals NHS Trust over a 10-month period (October 2018 to July 2019). Patients with a traumatic mode of injury or concurrent hip or pathological fracture were excluded from analysis.

\section{Results}

One hundred and twenty-five predominantly female (83\%) patients with an average age of 86 years presented with acute fragility fractures of the pubic rami on plain X-ray. Eighteen per cent were discharged direct from the emergency department, $47 \%$ were admitted under elderly medicine, $30 \%$ under trauma and orthopaedic, and 5\% under other specialties. Thirteen per cent had concurrent acetabular fractures identified on X-ray. Only $26 \%$ of patients received further pelvic imaging, by CT or MRI. In those patients who received further imaging, $88 \%$ confirmed acute pubic rami fractures, $41 \%$ showed acetabular fractures and $63 \%$ showed sacral fractures of all types. Three per cent $(n=1)$ showed fracture of the ilium. Overall, $53 \%$ of patients who received further imaging were diagnosed with a combined fracture of the public ramus and sacrum, and $9 \%(n=1)$ with a combined fracture of the pubic ramus and the ilium.

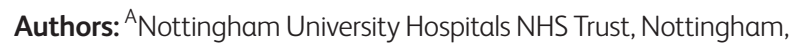

Furthermore, 23 patients had acute pelvic fragility fractures identified on CT or MRI, in the presence of normal X-rays. In these patients, further imaging showed that $70 \%$ had suffered pubic rami fractures, $22 \%$ acetabular fractures, $74 \%$ sacral fractures and $22 \%$ ilium fractures.

\section{Conclusion}

Pubic rami fragility fractures are a significant problem in older people and often require admission to hospital. Further imaging confirms that these fractures are complex, with co-existing fractures of the acetabulum and sacrum being common. Findings also confirm that plain X-rays are a poor modality in the identification of pelvic fractures. However, despite this, only a quarter of patients admitted had further imaging. Where pelvic fractures are missed or severity not appreciated, appropriate pain control can be more difficult to achieve. With the potential for minimally invasive surgical options to aid pain management in sacral fractures, it may be prudent for all patients hospitalised with suspected or confirmed pelvic fracture to undergo further imaging.

\section{Conflicts of interest}

None declared.

\section{References}

1 Kannus P, Palvanen M, Parkkari J, Niemi S, Järvinen M. Osteoporotic pelvic fractures in elderly women. Osteoporosis Int 2005;16:1304-5.

2 Alost T, Waldrop RD. Profile of geriatric pelvic fractures presenting to the emergency department. Am J Emerg Med 1997;15:576-8.

3 Alnaib M, Waters S, Shanshal Y et al. Combined pubic rami and sacral osteoporotic fractures: a prospective study. J Orthop Traumatol 2012;13:97-103.

4 Rommens PM, Wagner D, Hofmann A. Fragility fractures of the pelvis. JBJS Rev 2017;5:e3.

5 van Dijk WA, Poeze M, van Helden SH, Brink PRG, Verbruggen JPAM. Ten-year mortality among hospitalised patients with fractures of the pubic rami. Injury 2010;41:411-4.

6 Bayley E, Srinivas S, Boszczyk BM. Clinical outcomes of sacroplasty in sacral insufficiency fractures: a review of the literature. Eur Spine J 2009; 18:1266-71.

7 Frey ME, Warner C, Thomas SM et al. Sacroplasty: a ten-year analysis of prospective patients treated with percutaneous sacroplasty: literature review and technical considerations. Pain Physician 2017;20:E1063-72. 